\title{
Temperature and flow rate limit the optimal ex-vivo perfusion of the heart - an experimental study
}

\author{
Mohammed Quader ${ }^{1,2 \dagger}$, Juan Francisco Torrado ${ }^{2,3 \dagger}$, Martin J. Mangino ${ }^{1}$ and Stefano Toldo ${ }^{1,2^{*}}$
}

\begin{abstract}
Background: Ex-vivo heart perfusion can be utilized to study a variety of physiologic and molecular pathways in a controlled system outside of the body. It can also be used in clinical settings such as for organ preservation before transplantation. Myocardial oxygen consumption $\left(\mathrm{MVO}_{2}\right)$ correlates with energy production in the myocardium and can also be used to determine the balance between the oxygen supply and demand of the perfused heart. This study sought to determine an ex-vivo perfusion rate that matches the metabolic demands of the heart according to different temperatures and solution compositions (with and without the addition of erythrocytes), a flow below which the supply of oxygen is not sufficient to maintain an aerobic state of the perfused heart (" $\mathrm{D}_{\text {CRIT }}$ ").

Methods: Under general anesthesia, rat hearts were procured and preserved by perfusing with the University of Wisconsin Belzer machine perfusion system (UW Belzer MPS) solution saturated with $100 \% \mathrm{O}_{2}$. The key elements of this solution include supraphysiological potassium (to stop the heartbeat and reduce the cellular metabolic demand), starch, gluconate and mannitol (to maintain cell wall integrity), glucose (to sustain basal metabolism), and glutathione (to scavenge free radicals). Three groups of rat hearts $(n=7)$ were randomly allocated to be perfused at $15^{\circ} \mathrm{C}, 22^{\circ} \mathrm{C}$ or $37^{\circ} \mathrm{C}$, at a varying flow index (FI) starting from a minimum of $380 \mathrm{~mL} / \mathrm{min} / 100 \mathrm{~g}$ to less than $50 \mathrm{~mL} /$ min/100 g, decreasing by $50 \mathrm{~mL} / \mathrm{min} / 100 \mathrm{~g}$ at 10 min intervals while measuring the $\mathrm{MVO}_{2}$ at each $\mathrm{Fl}$. Lactate was measured from coronary sinus samples to determine the onset of tissue hypoxia/anaerobic state.

Results: The $D_{\text {CRIT }}$ at $15^{\circ} \mathrm{C}$ was $99.9 \pm 4.9 \mathrm{~mL} / \mathrm{min} / 100 \mathrm{~g}$; however, at $22^{\circ} \mathrm{C}$ and $37^{\circ} \mathrm{C}$ we could not reach a $D_{\text {CRIT }}$. The myocardial oxygen demand could not be met at $22^{\circ} \mathrm{C}$ and $37^{\circ} \mathrm{C}$ with the maximum Fl above $380 \mathrm{~mL} / \mathrm{min} / 100$ $\mathrm{g}$ even when erythrocytes $(10 \% \mathrm{VN})$ were added to the solution. At $15^{\circ} \mathrm{C}$, the production of lactate was evident only below the $\mathrm{D}_{\mathrm{CRIT}}$, while at $22^{\circ} \mathrm{C}$ lactate production was present at all flow indices.

(Continued on next page)
\end{abstract}

\footnotetext{
* Correspondence: stefano.toldo@vcuhealth.org

${ }^{\dagger}$ Mohammed Quader and Juan Francisco Torrado contributed equally to this work.

'Department of Surgery, Virginia Commonwealth University, Richmond, VA, USA

${ }^{2}$ Department of Cardiology, VCU Pauley Heart Center, Virginia Commonwealth University, Box 980281, Richmond, VA 23298, USA Full list of author information is available at the end of the article
}

(c) The Author(s). 2020 Open Access This article is licensed under a Creative Commons Attribution 4.0 International License, which permits use, sharing, adaptation, distribution and reproduction in any medium or format, as long as you give appropriate credit to the original author(s) and the source, provide a link to the Creative Commons licence, and indicate if changes were made. The images or other third party material in this article are included in the article's Creative Commons licence, unless indicated otherwise in a credit line to the material. If material is not included in the article's Creative Commons licence and your intended use is not permitted by statutory regulation or exceeds the permitted use, you will need to obtain permission directly from the copyright holder. To view a copy of this licence, visit http://creativecommons.org/licenses/by/4.0/ The Creative Commons Public Domain Dedication waiver (http://creativecommons.org/publicdomain/zero/1.0/) applies to the data made available in this article, unless otherwise stated in a credit line to the data. 
(Continued from previous page)

Conclusions: Determining the $D_{\text {CRIT }}$ for optimal ex-vivo perfusion of the heart is necessary to ensure adequate tissue oxygenation and limit anaerobic state. Temperatures employed above $15^{\circ} \mathrm{C}$ limit the efficient ex-vivo perfusion preservation of heart with the UW Belzer MPS solution.

Keywords: Myocardial oxygen consumption, Critical coronary flow, Organ preservation, Heart transplantation, Machine perfusion system, Crystalloid solution

\section{Background}

The myocardial oxygen consumption $\left(\mathrm{MVO}_{2}\right)$ correlates with energy utilization from the cells $[1,2]$. Therefore, during a steady-state, $\mathrm{MVO}_{2}$ is an indirect measure of the total energy utilization of the heart [1]. In a beating heart, $\mathrm{MVO}_{2}$ is primarily determined by heart rate, wall tension and contractility [3]. Experimental studies have shown that $\mathrm{MVO}_{2}$ of the arrested heart is approximately $20 \%$ of the contracting heart. This is attributed to the basal myocardial oxygen requirements needed to maintain critical membrane functions and basal metabolism [4]. Ex-vivo organ perfusion is an ideal experimental setting that allows the study of $\mathrm{MVO}_{2}$ in different controlled conditions, such as a beating or resting heart and at different temperatures. Since the heart will decrease its energy utilization if perfused sub-optimally (anaerobic state), measuring the $\mathrm{MVO}_{2}$ in itself, may not provide with certainty whether the oxygen demand of the heart is met or not. Determining the critical flow rate $\left(D_{\text {CRIT }}\right)$ above which the $\mathrm{O}_{2}$ demand of the heart is met is of paramount importance to prevent the state of myocardial hypoxia and for better organ preservation.

Classic perfusion preservation is a method of preserving organs ex-vivo prior to re-implantation in a recipient $[5$, 6]. The goals of perfusion preservation are to preserve cellular adenosine triphosphate (ATP) stores by reducing cell metabolism such as with hypothermia, along with supplying adequate oxygen delivery and nutrients, to maintain oxidative phosphorylation $[5,6]$. Temperature is one of the main parameters that determine the oxygen solubility in the perfusion solution. Oxygen solubility is higher at lower temperatures $[5,6]$. In addition, since temperature regulates the cellular metabolic rate, the $\mathrm{D}_{\text {CRIT }}$ varies by the temperature [7]. Despite the importance of the $\mathrm{D}_{\text {CRIT }}$, there is little to no attention paid to the flow index (FI) to be used during organ preservation or other ex-vivo experimental perfusion conditions [8]. In an optimal ex-vivo heart preservation condition the metabolic rate is reduced and adequate oxygen is delivered to maintain an aerobic state.

The objective of this study is to define the $D_{\text {CRIT }}$ of the rat heart perfused with University of Wisconsin Belzer machine perfusion system (UW Belzer MPS) solution at three temperatures.

\section{Methods \\ Experimental model}

This experimental study investigated the effect of different temperatures on the critical flow index $\left(\mathrm{D}_{\mathrm{CRIT}}\right)$ of isolated rat hearts in the experimental setting of a solution-perfused Langendorff apparatus. In addition, for those perfusing conditions that could not reach the $\mathrm{D}_{\text {CRIT }}$ (i.e., higher temperatures), we tested whether the addition of red blood cells may improve the oxygen delivery capacity in this setting and allow to match the oxygen demands of the myocardium.

\section{Heart procurement}

Adult male Sprague Dawley rats were selected for these experiments. A total of 21 rats were divided into three temperature groups $\left(15^{\circ} \mathrm{C}, 22^{\circ} \mathrm{C}\right.$, and $\left.37^{\circ} \mathrm{C}\right)$. General anesthesia was achieved by administering intramuscular Ketamine-Xylazine $(100-10 \mathrm{mg} / \mathrm{kg})$, followed by endotracheal intubation and systemic heparin $(500 \mathrm{U})$, which was administered into the tail vein.

Following a bilateral thoracotomy, the inferior vena cava (IVC) was cannulated with a $21 \mathrm{G}$ phlebotomy catheter, secured and left in place to be used for coronary sinus sample collection during the perfusion phase. The hearts were explanted and cleaned from the extracardiac tissue, leaving the inferior vena cava and the catheter in place. Next, a cannula was placed and secured into the ascending aorta. The heart mass was determined by subtracting the weight of the of the cannulas from the weight of the cannulated heart. The average heart weight was $1.22 \pm 0.05 \mathrm{~g}$. To increase the oxygen carrying capacity of the solution, two additional groups of hearts were perfused $\left(22^{\circ} \mathrm{C}\right.$ and $\left.37^{\circ} \mathrm{C}\right)$ with the MPS solution containing purified erythrocytes. Platelet rich plasma and erythrocytes were separated from rat blood by centrifuging heparinized blood at $400 \mathrm{x} g$. The erythrocyte rich phase was washed in phosphate buffered saline, centrifuged again at $1200 \times g$ and the purified erythrocytes were added at a $10 \% \mathrm{~V} / \mathrm{V}$. The experiments were conducted under the updated guidelines of the "Guide for the care and use of laboratory animals" [9]. The study protocol was approved by the Virginia Commonwealth Institutional Animal Care and Use Committee. 


\section{Machine perfusion system}

The machine perfusion (MPS) system was designed to perfuse the heart at varying flow rates. The UW Belzer MPS solution (Belzer MPS, Bridge to Life Ltd., Columbia, SC) was placed into a preservation solution reservoir and pushed into the system using a roller pump to deliver low volumes of solution (Fisher Scientific, Hampton, NH). The composition of the UW Belzer MPS solution is reported in Table 1. This is an isotonic solution that has a supraphysiological potassium concentration that maintains heart in diastolic arrest. It has been designed to reduce the cellular metabolic demand, reduce edema and maintain cell wall integrity, sustain basal metabolism and scavenge free radicals. The flow rate was measured using an in-line flow probe (AD instrument), following passage through an oxygenator (adapted from a Hemofilter D150, Medica, Monza, Italy). Placement of a cooling/heating chamber in front of the heart cannula enabled collection of sample solution with a 3-way stop-cock before entering the heart (input solution). The aortic cannula perfused the heart while the inferior vena cava cannula collected the perfusate exiting the coronary sinus (output solution). A simplified schema of the experimental protocol and MPS is represented in Fig. 1.

The partial pressure of $\mathrm{O}_{2}$ in the input MPS solution $\left(\mathrm{PaO}_{2}\right)$ was above $700 \mathrm{mmHg}$ at $15^{\circ} \mathrm{C}$ (mean $\mathrm{PaO}_{2}$ $724 \pm 24)$, above $650 \mathrm{mmHg}$ at $22^{\circ} \mathrm{C}\left(\right.$ mean $\mathrm{PaO}_{2} 766 \pm$ 27), and above $450 \mathrm{mmHg}$ at $37^{\circ} \mathrm{C}$ (mean $\mathrm{PaO}_{2} 526 \pm$ $55)$. The differences in these partial pressure values are due to the effect of temperature on oxygen solubility in a non-blood based solution. Flow values were expressed as FI as a standard measure for organ perfusion. All hearts in this study were set at an initial FI of at least $380 \mathrm{~mL} / \mathrm{min} / 100 \mathrm{~g}$, equivalent to a flow rate of at least

Table 1 Composition of the UW Belzer MPS solution

\begin{tabular}{ll}
\hline CONSTITUENT & CONCENTRATION \\
\hline Adenine (free base) & $5(\mathrm{mmol} / \mathrm{L})$ \\
Calcium Chloride (dihydrate) & $0.5(\mathrm{mmol} / \mathrm{L})$ \\
Glucose & $10(\mathrm{mmol} / \mathrm{L})$ \\
Glutathione (reduced) & $3(\mathrm{mmol} / \mathrm{L})$ \\
HEPES (free acid) & $10(\mathrm{mmol} / \mathrm{L})$ \\
Hydroxyethyl Starch & $50(\mathrm{~g} / \mathrm{L})$ \\
Magnesium Gluconate (anhydrous) & $5(\mathrm{mmol} / \mathrm{L})$ \\
Mannitol & $30(\mathrm{mmol} / \mathrm{L})$ \\
Potassium Phosphate (monobasic) & $25(\mathrm{mmol} / \mathrm{L})$ \\
Ribose, D(-) & $5(\mathrm{mmol} / \mathrm{L})$ \\
Sodium Gluconate & $80(\mathrm{mmol} / \mathrm{L})$ \\
Sodium Hydroxide & $0.7(\mathrm{~g} / \mathrm{L})$ \\
Sterile Water for Injection & To $1 \mathrm{~L} \mathrm{final} \mathrm{volume}$ \\
\hline
\end{tabular}

$3.8 \mathrm{ml} / \mathrm{g} / \mathrm{min}$. Input and output perfusate samples were collected $10 \mathrm{~min}$ from the beginning of the perfusion, using ice-cold $1 \mathrm{~mL}$ syringes. The syringes were capped with parafilm, placed on ice and rapidly analyzed $(<1$ min) with the ABL-800 blood gas analyzer (Radiometer, Copenhagen, Denmark). Rigorous steps such as, precooling, sealing and rapid reading, were necessary to ensure reliable readings from the samples. The perfusate flow rate was decreased by approximately $40-60 \mathrm{~mL} /$ $\mathrm{min} / 100 \mathrm{~g}$, or $0.4-0.6 \mathrm{ml} / \mathrm{g} / \mathrm{min}$, every $10 \mathrm{~min}$ after each measurement, until reaching the lowest perfusion rate allowed by the pump $(30-40 \mathrm{~mL} / \mathrm{min} / 100 \mathrm{~g}$, or $0.3-0.4$ $\mathrm{ml} / \mathrm{g} / \mathrm{min}$ ).

Flow rate and temperature of perfusate were monitored continuously with a Power Lab data acquisition system (AD Instruments, Denver, CO). $\mathrm{MVO}_{2}$ values were calculated at each FI using the Fick equation $\left[\left(\mathrm{CaO}_{2}-\mathrm{CvO}_{2}\right) \times\right.$ flow / heart weight $]$, where $\mathrm{CaO}_{2}$ and $\mathrm{CvO}_{2}$ represent the concentration of $\mathrm{O}_{2}$ in the input and output solution, respectively. $\mathrm{MVO}_{2}$ and FI values were plotted in a graph. Initiation of the anaerobic phase is represented by the corresponding FI $\left(D_{\text {CRIT }}\right)$ when $\mathrm{MVO}_{2}$ becomes flow limited. The exact value of the $\mathrm{D}_{\text {CRIT }}$ was determined from the best fit lines of the points in the plateau phase (aerobic, above the $\mathrm{D}_{\mathrm{CRIT}}$ ) and the line derived in the flow limited part of the curve (anaerobic, below the $\mathrm{D}_{\text {CRIT }}$ ) (Fig. 2) [10]. The FI corresponding to the point when $\mathrm{MVO}_{2}$ drops to become flow limited represents $D_{\text {CRIT }}$. However, when the $\mathrm{MVO}_{2}$ always remained flow limited (never reached a stable plateau phase) we could not determine the $\mathrm{D}_{\mathrm{CRIT}}$ for the FI used.

\section{Lactate measurement}

Lactate levels were measured in the perfusate samples using the ABL-800 blood gas analyzer at all FI. Lactate production was compared by using area under the curve for Lactate and FI for heart groups perfused at $15^{\circ} \mathrm{C}$ and $22{ }^{\circ} \mathrm{C}$.

\section{Statistical analysis}

Values were expressed as the mean value and standard error of the mean (SEM). The sample size was not determined a priori. The statistical analysis was performed using Statistical Package for Social Sciences (SPSS version 24.0 for Mac, Chicago, IL). Differences between groups were assessed using two-tailed Student's T test for unpaired data. Linear regression analyses were used to assess the relationship between $\mathrm{MVO}_{2}$ and FI. Linear equations for the lines of best fit were used to determine the $\mathrm{D}_{\text {CRIT }}$ if a plateau of $\mathrm{MVO}_{2}$ was reached. $P<0.05$ indicates significant statistical differences. 

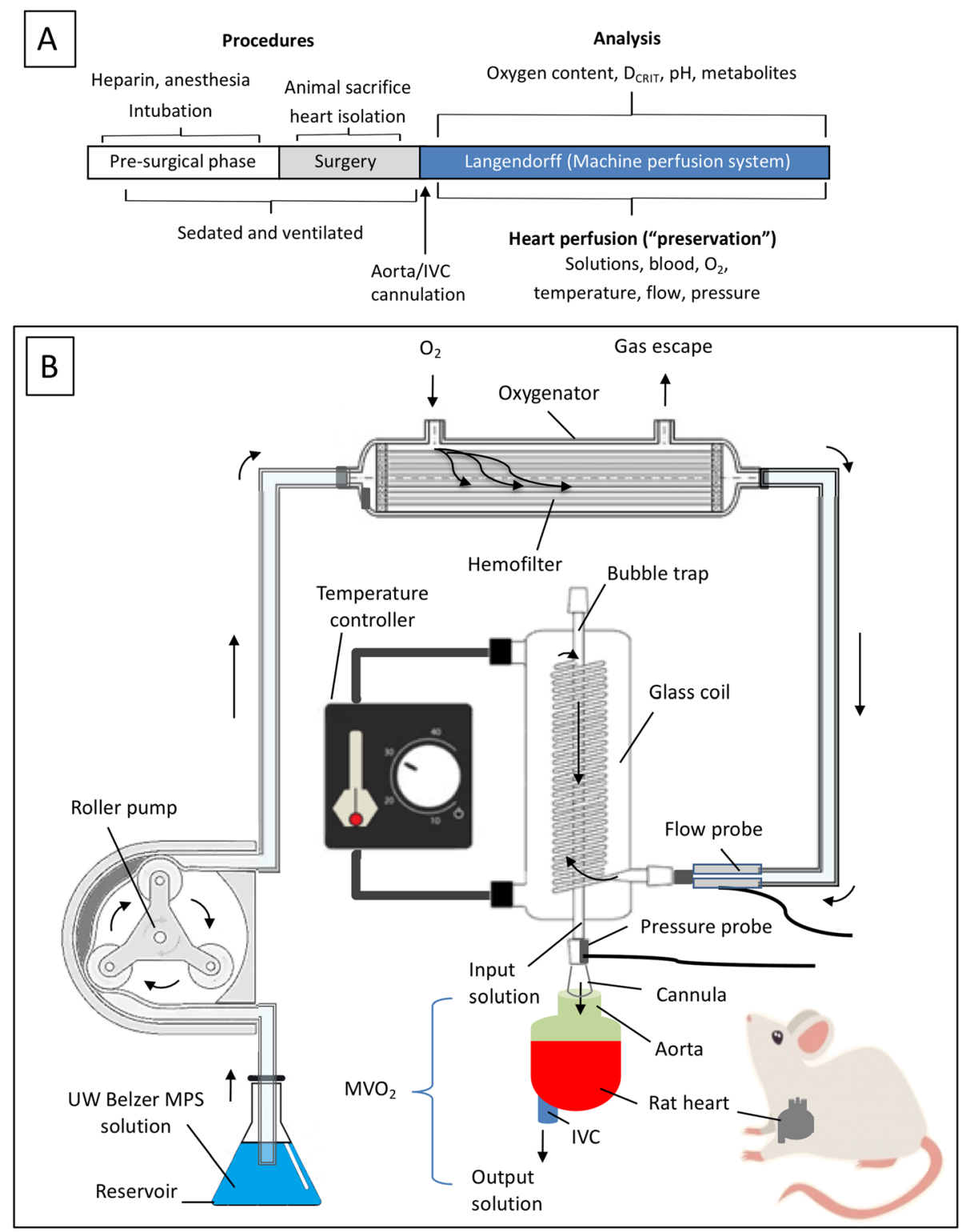

Fig. 1 Simplified schema of the experimental design and protocol. Panel a. Experimental protocol employed to determine the ex-vivo critical flow index $\left(\mathrm{D}_{\mathrm{CRIT}}\right)$ of isolated rat hearts according to changes in the composition and temperature of the perfusate. Panel $\mathbf{b}$. The machine perfusion apparatus is primed with oxygenated UW Belzer MPS solution at the desired temperature by using a recirculating temperature controller and glass heat exchanger coil. Hearts are attached to the apparatus, and antegrade coronary flow is initiated via the aortic cannula at a controlled flow index (FI) by using a roller pump. Oxygen transfer to the perfusate is maintained by passing the solution through a pediatric hollow fiber hemofilter with a continuous oxygen sweep delivered across the outer compartment. Flow rate, flow pressure, and temperature of perfusate are monitored continuously. Input (aortic) and output solution (inferior vena cava) samples are collected serially to assess variables of interest

\section{Results}

\section{Effects of temperature on the $\mathrm{FI} / \mathrm{MVO}_{2}$ relationship}

Figure 3 shows the relationship between the FI and $\mathrm{MVO}_{2}$ at $15^{\circ} \mathrm{C}, 22^{\circ} \mathrm{C}$ and $37^{\circ} \mathrm{C}$ using UW Belzer MPS solution. We determined that at $15^{\circ} \mathrm{C}$ the $\mathrm{D}_{\mathrm{CRIT}}$ is $99.9 \pm 4.9 \mathrm{~mL} / \mathrm{min} / 100 \mathrm{~g}$ of myocardial tissue, or $1.0 \mathrm{ml} /$ gram heart tissue. At this temperature, the $\mathrm{MVO}_{2}$ above the $\mathrm{D}_{\text {CRIT }}$ was $1.49 \pm 0.05 \mathrm{~mL} / \mathrm{min} / \mathrm{g}$ with no further increase in $\mathrm{MVO}_{2}$ with higher FI. This data shows that during perfusion with UW Belzer MPS solution at $15^{\circ} \mathrm{C}$ the oxygen need of the heart can be met by perfusing above the $\mathrm{D}_{\text {CRIT }}$. For the $22^{\circ} \mathrm{C}$ and $37^{\circ} \mathrm{C}$ temperatures, the relationship between $\mathrm{MVO}_{2}$ and FI was linear and never reached a steady-state. This data was corroborated 


\section{$\mathrm{MVO}_{2}$ at preservable temperature}

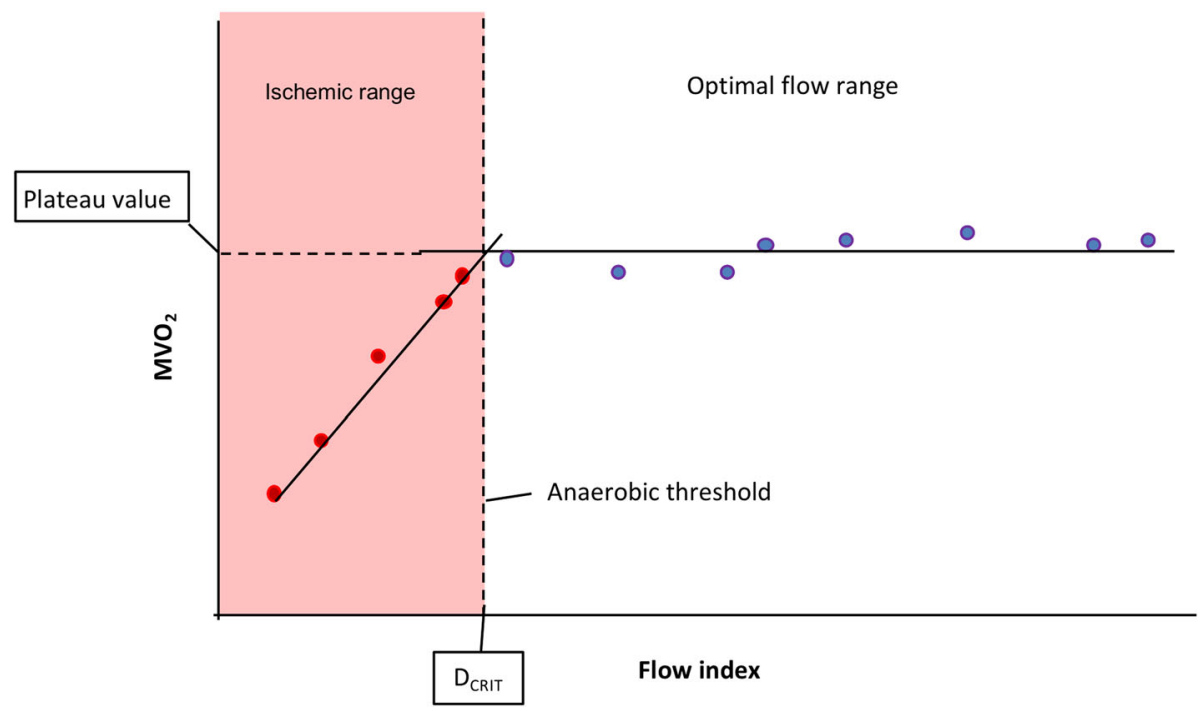

Fig. 2 Illustration depicting the $D_{\text {CRIT }}$ in ex-vivo heart perfusion models. The point above which oxygen extraction is flow independent is $D_{C R I T}$. The isolated heart could not be efficiently preserved below this critical flow index since it will become hypoxic/ischemic (below "anaerobic threshold") leading to lactic acidosis, impaired microcirculation and tissue damage. The "plateau value" (maximum $\mathrm{MVO}_{2}$ in relation with the temperature of the perfusate) is achieved once the critical flow value is exceeded ensuring optimal perfusion conditions

by the analysis of the lactate levels measured in the output solution at $15^{\circ} \mathrm{C}$ and $22^{\circ} \mathrm{C}$ (Fig. 4). At $15^{\circ} \mathrm{C}$, there was no lactate production in the steady-state and flowindependent phase (above the $\mathrm{D}_{\mathrm{CRIT}}$ ), while lactate levels increased consistently when the flow dropped below the $\mathrm{D}_{\text {CRIT }}$. On the other hand, at $22^{\circ} \mathrm{C}$ there was lactate production in most of the samples at every FI analyzed. Considering these observations, lactate production in the solutions at $37^{\circ} \mathrm{C}$ was predictable and not necessary to be analyzed. The difference in lactate levels between the two temperatures was significant, as shown by the analysis of the area under the curve for the lactate production at the different FI investigated (Fig. 4).

\section{Addition of erythrocytes to the MPS solution}

In separate groups of hearts, we added erythrocyte to the UW Belzer MPS solution at $22^{\circ} \mathrm{C}$ and $37^{\circ} \mathrm{C}$, to determine whether adding an oxygen carrier could improve oxygen delivery to the heart perfused in the MPS system. Table 2 shows the input $\mathrm{O}_{2}$ concentration $\left(\mathrm{CaO}_{2}\right)$ and the amount of hemoglobin measured in the perfusion solution. Despite the increase in $\mathrm{O}_{2}$ concentration in the input solution, adding the erythrocytes was insufficient to establish an aerobic metabolism, since the hearts did not reach a $\mathrm{D}_{\text {CRIT }}$ at the FI we analyzed (Fig. 5).

\section{Discussion}

$\mathrm{MVO}_{2}$ is a useful parameter measured to assess energy production and utilization by the myocardial tissue [1,
2]. In this study, we have used the $\mathrm{MVO}_{2}$ to determine the conditions of adequate myocardial perfusion and preservation. We investigated the relationship that exist between temperature, FI and $\mathrm{MVO}_{2}$ in hearts perfused with UW Belzer MPS solution with the goal to determine the critical flow, or $\mathrm{D}_{\mathrm{CRIT}}$, above which the myocardial oxygen demand is met. This study was performed because we felt that most of the studies performed using ex vivo perfusion are designed based on empirically determined observations that may underestimate the importance of perfusion flows, pressures or temperatures used. Such parameters may in fact limit the optimal oxygen delivery to the heart, which in turn may alter the tissue response to injury and or therapeutic treatments. Prior work has been performed to determine the $\mathrm{D}_{\text {CRIT }}$ in other organs $[11,12]$. Those studies were performed using blood based perfusate in normothermic conditions. However, to our knowledge, ours is the first of such studies determining the Dcrit in the normal heart in different conditions.

We used a machine perfusion system model in combination with a cardioplegia (UW Belzer MPS solution) to exert control on all the parameters that may affects the oxygen use in the myocardium. An arrested heart has an $80 \% \mathrm{MVO}_{2}$ lower compared to the contracting heart [4]. Interestingly, we found that the oxygen demand of a non-beating rat heart is met at a temperature of $15^{\circ} \mathrm{C}$ using a flow above $100 \mathrm{~mL} / \mathrm{min} / 100 \mathrm{~g}$ of tissue, or $1.0 \mathrm{ml} / \mathrm{gram}$, but not when perfusing the rat heart at 


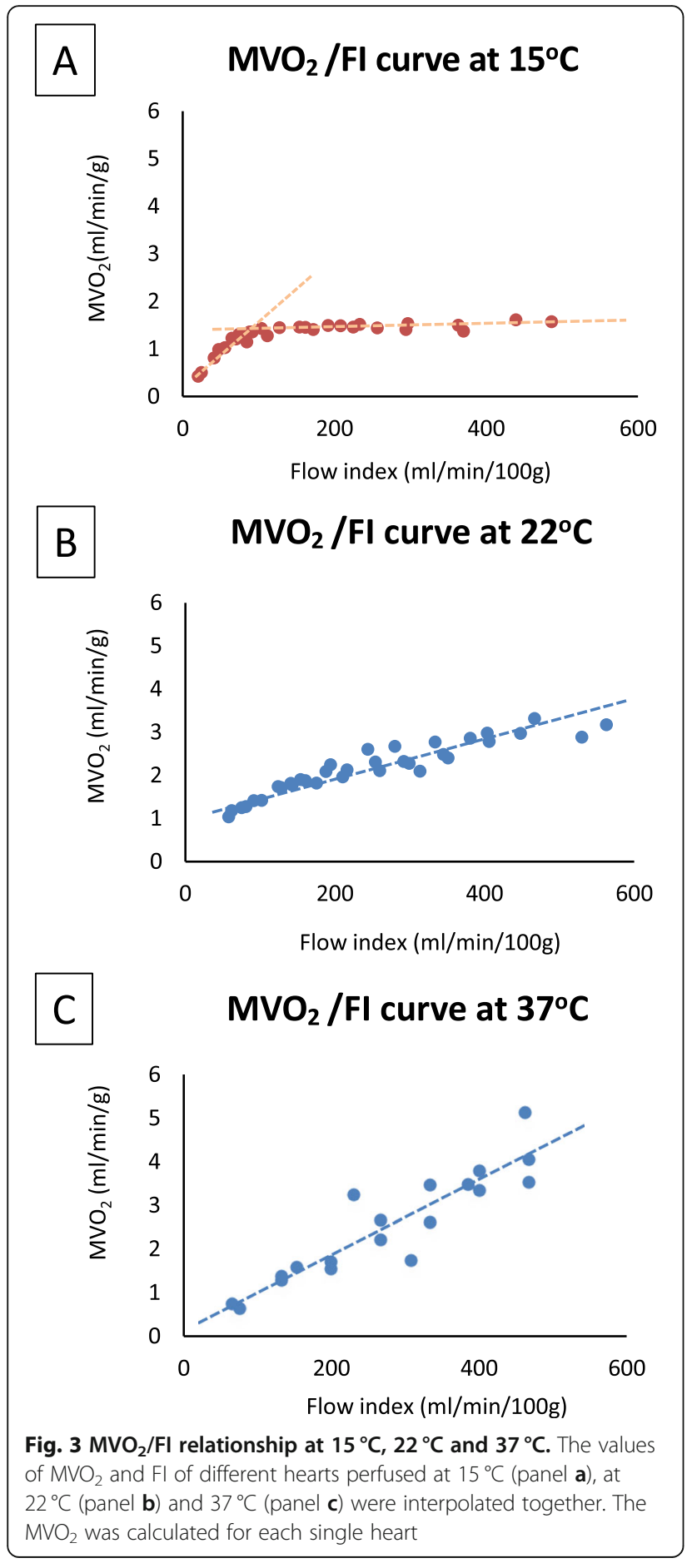

$22^{\circ} \mathrm{C}$ or higher temperatures with UW Belzer MPS solution. This result is particularly important because it shows that perfusion of the rat heart with UW Belzer MPS solution at temperatures of $22^{\circ} \mathrm{C}$ and higher is flow limited and the heart produces lactate at the higher FI (i.e., perfusing conditions below anaerobic threshold). We used erythrocytes to increase the oxygen delivery to
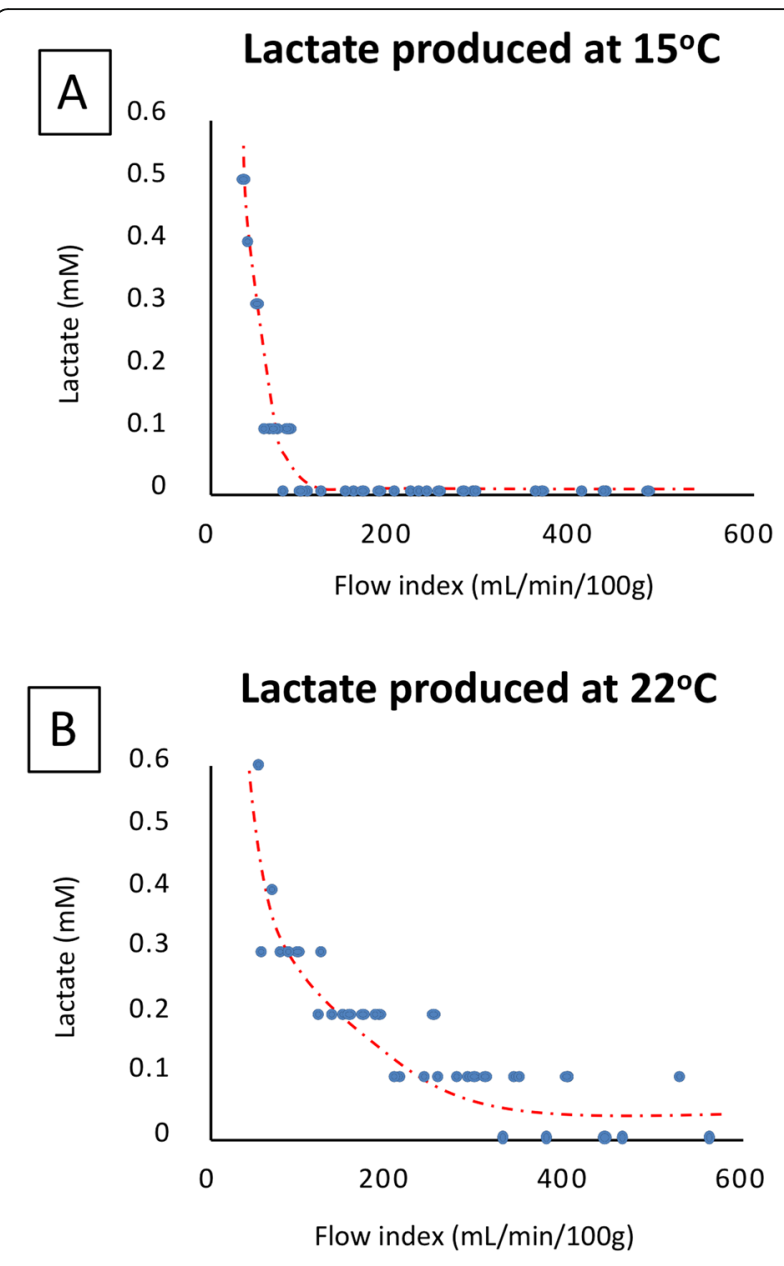

C Area under the curve

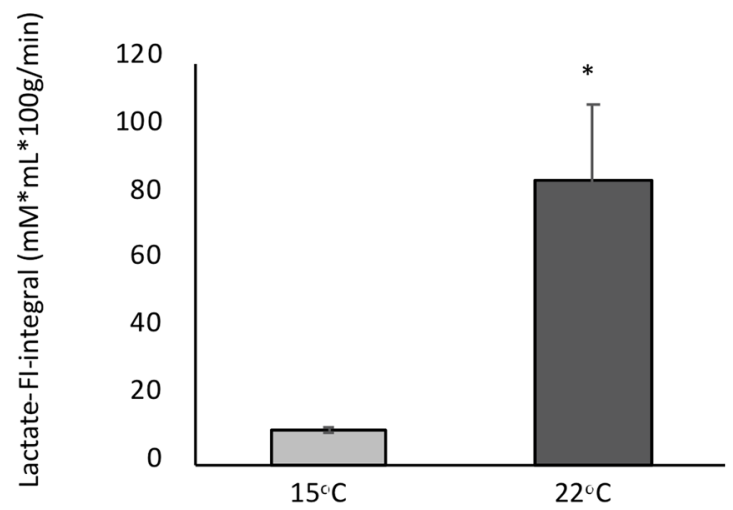

Fig. 4 Lactate production. The graphs show the levels of lactate measured at each flow index analyzed during perfusion at $15^{\circ} \mathrm{C}$ (panel a) and $22^{\circ} \mathrm{C}$ (panel $\mathbf{b}$ ). Panel $\mathbf{c}$ shows the value of the area under the curve (AUC) of lactate over the different range of flow indexes used and reported as mean \pm SEM. ${ }^{*} p<0.02$ for $15^{\circ} \mathrm{C}$ vs $22^{\circ} \mathrm{C}$. The red dashed lines in panel $\mathbf{a}$ and panel $\mathbf{b}$ show the different trend of distribution of the plotted points in the two condition 
Table 2 Input $\mathrm{O}_{2}$ concentration $\left(\mathrm{CaO}_{2}\right)$ of the MPS solutions with and without the addition of erythrocytes

\begin{tabular}{lllll}
\hline & $22^{\circ} \mathrm{C}$ MPS solution & $22^{\circ} \mathrm{C}$ MPS solution + Erythrocytes & $37^{\circ} \mathrm{C} \mathrm{MPS}$ solution & $37^{\circ} \mathrm{C}$ MPS solution + Erythrocytes \\
\hline $\mathrm{CaO}_{\mathbf{2}}(\mathbf{m L} / \mathbf{d L})$ & $2.17 \pm 0.07^{* \wedge \wedge}$ & $3.14 \pm 0.27$ & $1.58 \pm 0.16^{*}$ & $2.69 \pm 0.30$ \\
$\mathbf{H b}(\mathbf{g} / \mathbf{d L})$ & N/A & $0.79 \pm 0.20$ & N/A & $0.73 \pm 0.19$
\end{tabular}

Data are expressed as mean \pm SEM. ${ }^{*} p<0.05$ for MPS solution vs MPS solution + Erythrocytes; $\wedge p<0.05$ for $22^{\circ} \mathrm{C}$ vs $37^{\circ} \mathrm{C}$.

Abbreviations: MPS machine perfusion system, $\mathrm{CaO}_{2}$ input $\mathrm{O}_{2}$ concentration, $\mathrm{Hb}$ hemoglobin, $\mathrm{N} / \mathrm{A}$ not applicable

the heart and, interestingly, the $\mathrm{MVO}_{2}$ did not change in this condition. The inability to reach the $\mathrm{D}_{\mathrm{CRIT}}$ with the addition of erythrocytes could be due to insufficient amount of erythrocytes in perfusate or due to impaired oxygen delivery at the level of the microcirculation, possibly related to hemo-rheological disturbances such impaired red blood cell deformability, increased cell aggregation and vasoconstriction, all leading to microvascular occlusion [13-17].

The use of a cardioplegia, like the UW Belzer MPS solution, eliminates differences in myocardial oxygen

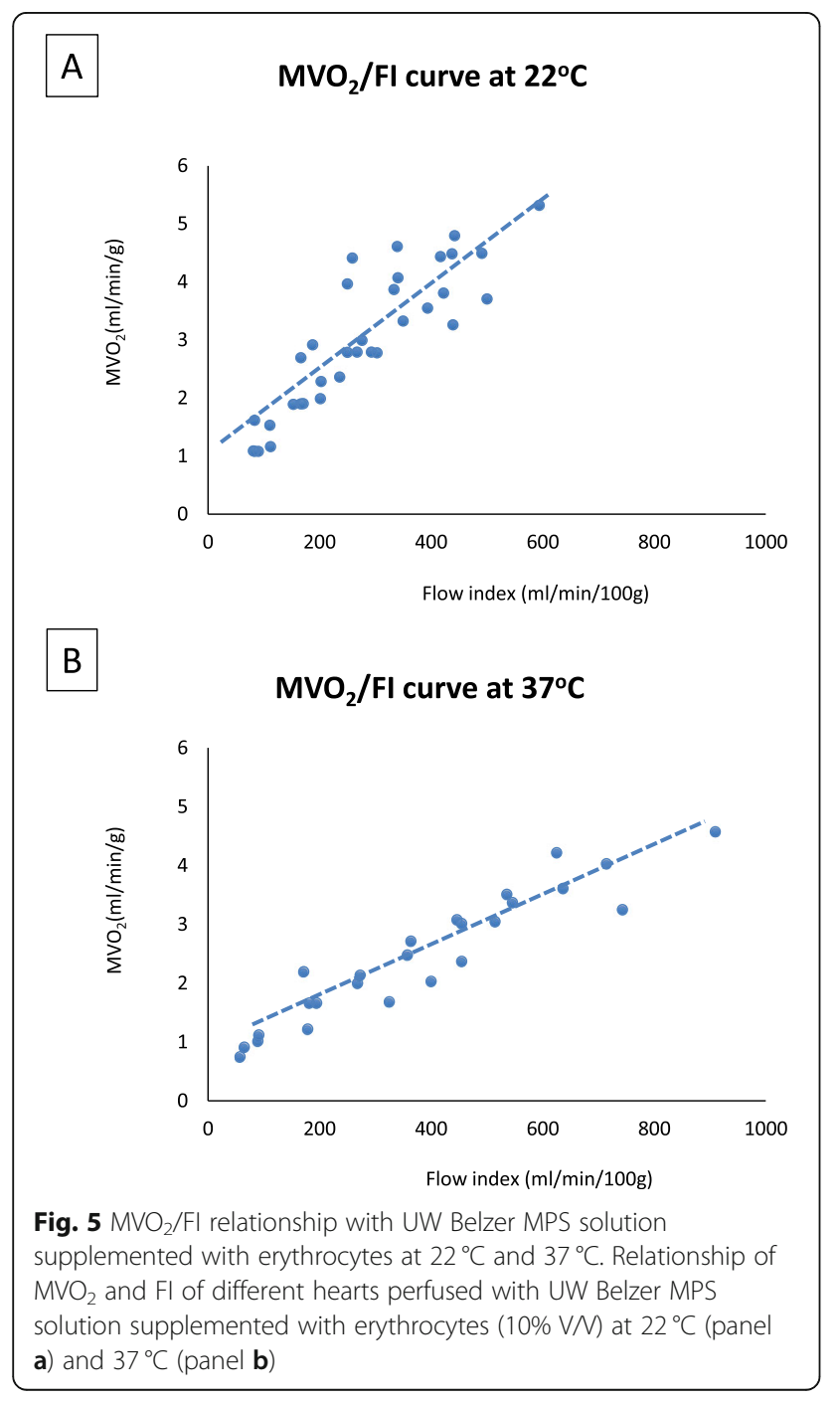

demand due to the cardiac contractility. The UW Belzer MPS solution is a colloid solution that contains glucose, adenine, ribose and phosphates to supplement the heart with basic elements to produce energy. This solution has been developed for kidney perfusion at $4{ }^{\circ} \mathrm{C}$. However, the UW Belzer MPS is very similar to the UW cold storage storage solution, which has been used in human heart transplantation and in experimental studies in the preclinical setting [18-20]. Due to optimization for the machine perfusion system, the UW Belzer MPS has been the solution of choice in this study. It is noteworthy that if an arrested heart could not be kept in aerobic condition above $15^{\circ} \mathrm{C}$ then it is not practical to expect a reanimated heart to remain in aerobic condition while perfused with non-blood based perfusates. A blood based ex vivo perfusion model will carry sufficient oxygen to keep even a reanimated heart in aerobic condition but it has its own limitations [21, 22]. Many a times, an additional animal needed to be sacrificed to prime the blood based ex-vivo circuit, this will add cost and a need for justification for additional animals. The blood is known to hemolyze in roller pumps leading to deposition of heme in the myocardial capillaries and limiting even distribution of perfusate. Since the blood based circuit is recycled after certain duration the metabolic substrate is depleted and a continuous addition of substrate becomes necessary [23]. In view of these challenges, the majority of small animal ex-vivo heart perfusion studies were done with non-blood based perfusates. Our observations are particularly important for perfusion preservation studies, because our results show that above $22^{\circ} \mathrm{C}$ the rat heart cannot be efficiently preserved with UW Belzer MPS solution, and that for a temperature of $15^{\circ} \mathrm{C}$ there is a minimum FI requirement, below which the heart becomes ischemic. Our results suggest that ex-vivo perfusion of hearts need to be carefully planned, by determining the Dcrit of the heart, that most likely varies with the species or size and metabolism of the heart tested. Conditions like temperature may pose some limitation to the ex-vivo perfusion of the heart (and virtually every other organ). Some of the implications of our study can be extended to the field of organ preservation in the setting of donation after brain death (DBD) or donation after circulatory death (DCD). Cold storage of a DBD heart is associated with a risk of preservation injury, and 
perfusion preservation may be superior to cold storage due to the avoidance of cold ischemia [24]. Experimental studies have shown that cold storage is detrimental for DCD hearts, and perfusion preservation can be a suitable strategy for such hearts [25, 26]. Therefore, our platform can be used to define the best preservation conditions for both DBD and DCD donors.

\section{Limitations}

We did not investigate further the relationship between the FI and $\mathrm{MVO}_{2}$ at temperatures lower than $15^{\circ} \mathrm{C}$. However, we can speculate that the heart can be safely perfused meeting its oxygen demand by perfusing at a FI above the $\mathrm{D}_{\text {CRIT }}$ defined here. In addition, the inability to reach the critical flow index of the isolated rat hearts with the addition of erythrocytes at higher perfusing temperatures could be explained by having used insufficient hematocrit; perhaps increasing more red blood cells may have allowed us to attain $\mathrm{D}_{\mathrm{CRIT}}$. Again, although blood is theoretically an ideal perfusate for hearts with natural buffers and antioxidants [21], the use of blood-based perfusates in small animal ex-vivo heart perfusion studies is challenging. In addition, blood-based perfusion solutions are prone to hemolyze, for which hemoglobin equivalents or substitutes, as well as synthetic oxygen carrier-based solutions, would be attractive. Future studies using the $\mathrm{O}_{2}$ carriers might allow us to achieve $D_{\text {CRIT }}$ at higher temperatures, thus eliminating the tight temperature control needed to conduct these experiments with currently available crystalloid-based perfusate. In a prior study, we utilized a modified version of the UW Belzer MPS solution, containing polyethylene glycol $20 \mathrm{~K}$ (instead of starch), adenosine Na-octanoate and aminoacids, where we could measure a $\mathrm{D}_{\mathrm{CRIT}}$ at $22^{\circ} \mathrm{C}[10]$, but not at higher temperatures (data not shown). Our results imply that during normothermic perfusions with physiological crystalloid buffers like the Krebs-Henseleit (K-H), which allows spontaneous development of the heartbeats, the heart is perfused under hypoxic/ischemic conditions. This may explain why following perfusion with the $\mathrm{K}-\mathrm{H}$ buffer, the heart function steadily declines with time [27].

\section{Conclusions}

Determining the $\mathrm{D}_{\mathrm{CRIT}}$ for optimal ex-vivo perfusion of the heart is necessary to ensure adequate tissue oxygenation and limit anaerobic state. In the investigated isolated rat heart model, the use of UW Belzer MPS solutions at $15^{\circ} \mathrm{C}$ allows optimal conditions for the machine perfusion system to exceed the $\mathrm{D}_{\text {CRIT }}$ and limit tissue damage. Temperatures employed above $15^{\circ} \mathrm{C}$ limit the efficient ex-vivo perfusion preservation of the heart, even with the addition of erythrocytes to the MPS solution.

\section{Abbreviations}

$\mathrm{CaO}_{2}$ : Input $\mathrm{O}_{2}$ concentration; $\mathrm{D}_{\mathrm{CRIT}}$ : Critical flow index; Fl: Flow index; $\mathrm{Hb}$ : Hemoglobin; IVC: Inferior vena cava; K-H: Krebs-Henseleit; $\mathrm{MVO}_{2}$ : Myocardial oxygen consumption; SEM: Standard error of the mean; UW Belzer MPS: University of Wisconsin Belzer machine perfusion system

\section{Acknowledgments}

We would like to thank Feranmi Akande for the help with database management and critical review of the perfusion data.

\section{Authors' contributions \\ $M Q$, JT, MM and ST designed and coordinated the study. ST and JT carried out the experiments and data collection. ST and JT wrote the manuscript, carried out the statistical analyses and designed the Figs. MQ, JT, MM and ST revised the manuscript critically and approved it finally.}

\section{Funding}

MQ was supported by an American Heart Association Scientist Development Grant, a VA Merit grant and a VCU Pauley Heart Center Pilot Study award. ST was supported by a grant from the Virginia Commonwealth University's CTSA (UL1TR000058 from the National Center for Advancing Translational Sciences) and the CCTR Endowment Fund of Virginia Commonwealth University, a Department of Internal Medicine Pilot Study Award and a Pauley Heart Center Pilot Study award.

Availability of data and materials

All data generated or analyzed during this study are included in this published article.

Ethics approval and consent to participate

All experiments were approved by the Virginia Commonwealth Institutional Animal Care and Use Committee.

\section{Consent for publication}

Not applicable.

\section{Competing interests}

The authors declare that they have no competing interests. All authors confirm that they had full control of the design and the methods of the study, the data analysis and the production of the written report.

\section{Author details}

'Department of Surgery, Virginia Commonwealth University, Richmond, VA, USA. ${ }^{2}$ Department of Cardiology, VCU Pauley Heart Center, Virginia Commonwealth University, Box 980281, Richmond, VA 23298, USA. ${ }^{3}$ Department of Cardiology, Clinic Hospital, School of Medicine, Republic University, Montevideo, Uruguay.

Received: 13 January 2020 Accepted: 13 July 2020

Published online: 22 July 2020

\section{References}

1. Braunwald E. 50th anniversary historical article. Myocardial oxygen consumption: the quest for its determinants and some clinical fallout. J Am Coll Cardiol. 1999:34(5):1365-8.

2. Izzi G, Zile MR, Gaasch WH. Myocardial oxygen consumption and the left ventricular pressure-volume area in normal and hypertrophic canine hearts. Circulation. 1991;84(3):1384-92.

3. Saito D, Yasuhara K, Nishiyama O, Kusachi S, Haraoka S. Comparative effects of heart rate and aortic blood pressure on MVO in the anesthetized openchest dog. Jpn Heart J. 1981;22(5):833-7.

4. Braunwald E. Control of myocardial oxygen consumption: physiologic and clinical considerations. Am J Cardiol. 1971;27(4):416-32.

5. Collins MJ, Moainie SL, Griffith BP, Poston RS. Preserving and evaluating hearts with ex vivo machine perfusion: an avenue to improve early graft performance and expand the donor pool. Eur J Cardiothorac Surg. 2008: 34(2):318-25.

6. Bruinsma BG, Yeh H, Ozer S, Martins PN, Farmer A, Wu W, et al. Subnormothermic machine perfusion for ex vivo preservation and recovery of the human liver for transplantation. Am J Transplant Off J Am Soc Transplant Am Soc Transplant Surg. 2014;14(6):1400-9. 
7. Ishikawa J, Oshima M, Iwasaki F, Suzuki R, Park J, Nakao K, et al. Hypothermic temperature effects on organ survival and restoration. Sci Rep. 2015:5:9563.

8. Chew HC, Macdonald PS, Dhital KK. The donor heart and organ perfusion technology. J Thoracic Dis. 2019;11(Suppl 6):S938-s45.

9. Sikes RS. 2016 guidelines of the American Society of Mammalogists for the use of wild mammals in research and education. J Mammal. 2016;97(3):663-88.

10. Quader M, Toldo S, Torrado J, Mishra S, Mauro AG, Mezzaroma E, et al. Determination of optimal coronary flow for the preservation of "donation after circulatory death" in murine heart model. ASAIO J (American Society for Artificial Internal Organs : 1992). 2018;64(2):225-31.

11. Desai TR, Sisley AC, Brown S, Gewertz BL. Defining the critical limit of oxygen extraction in the human small intestine. J Vasc Surg. 1996:23(5):832-7.

12. Kohzuki H, Enoki Y, Ohga Y, Shimizu S, Sakata S. Oxygen consumption in resting dog gracilis muscle perfused at varying oxygen delivery. Jpn J Physiol. 1991;41(1):23-34.

13. Lecklin T, Egginton $\mathrm{S}$, Nash GB. Effect of temperature on the resistance of individual red blood cells to flow through capillary-sized apertures. Pflugers Arch. 1996;432(5):753-9.

14. McHedlishvili G, Varazashvili M, Gobejishvili L. Local RBC aggregation disturbing blood fluidity and causing stasis in microvessels. Clin Hemorheol Microcirc. 2002;26(2):99-106.

15. Nemeth N, Furka I, Miko I. Hemorheological changes in ischemiareperfusion: an overview on our experimental surgical data. Clin Hemorheol Microcirc. 2014;57(3):215-25.

16. Seiyama A, Suzuki Y, Maeda N. Increased viscosity of erythrocyte suspension upon hemolysis. Colloid Polym Sci. 1993;271:63-9.

17. Olia SE, Maul TM, Antaki JF, et al. Mechanical blood trauma in assisted circulation: sublethal RBC damage preceding hemolysis. Int J Artif Organs. 2016;39(4):150-9.

18. Karck M, Vivi A, Tassini M, Schwalb H, Askenasy N, Navon G, Borman JB, Uretzky $\mathrm{G}$. The effectiveness of University of Wisconsin solution on prolonged myocardial protection as assessed by phosphorus 31-nuclear magnetic resonance spectroscopy and functional recovery. J Thorac Cardiovasc Surg. 1992;104(5):1356-64.

19. Mankad PS, Severs NJ, Lachno DR, Rothery S, Yacoub MH. Superior qualities of University of Wisconsin solution for ex vivo preservation of the pig heart. J Thorac Cardiovasc Surg. 1992;104(2):229-40.

20. Kur F, Beiras-Fernandez A, Meiser B, Uberfuhr P, Reichart B. Clinical heart transplantation with extended preservation time ( $>5$ hours): experience with University of Wisconsin solution. Transplant Proc. 2009;41(6):2247-9.

21. White CW, Hasanally D, Mundt P, Li Y, Xiang B, Klein J, et al. A whole bloodbased perfusate provides superior preservation of myocardial function during ex vivo heart perfusion. J Heart Lung Transplant. 2015;34(1):113-21.

22. Church JT, Alghanem F, Deatrick KB, Trahanas JM, Phillips JP, Hee Song M, et al. Normothermic ex vivo heart perfusion: effects of live animal blood and plasma cross circulation. ASAIO J (American Society for Artificial Internal Organs : 1992). 2017;63(6):766-73.

23. Sutherland FJ, Hearse DJ. The isolated blood and perfusion fluid perfused heart. Pharmacol Res. 2000;41(6):613-27.

24. Quader M, Hawkins RB, Mehaffey JH, Mazimba S, Ailawadi G, Yarboro L, Rich J, Speir A, Fonner C, Wolfe L, Kasirajan V. Investigators for the Virginia cardiac services quality initiative. Primary graft dysfunction after heart transplantation: outcomes and resource utilization. J Card Surg. 2019;34(12):1519-25.

25. Choong JW, Ou R, Lim YW, Rosenfeldt FL. Cold crystalloid perfusion provides cardiac preservation superior to cold storage for donation after circulatory death. Transplantation. 2016;100:546-53.

26. Rosenfeldt F, Ou R, Woodard J, Esmore D, Marasco S. Twelve-hour reanimation of a human heart following donation after circulatory death. Heart Lung Circ. 2014;23:88-90.

27. Jackson SJ, Pu LQ, Guerraty A, Symes JF. Cardiac preservation by continuous perfusion of the University of Wisconsin solution. Can J Surg. 1992;35(2):165-8.

\section{Publisher's Note}

Springer Nature remains neutral with regard to jurisdictional claims in published maps and institutional affiliations.

Ready to submit your research? Choose BMC and benefit from:

- fast, convenient online submission

- thorough peer review by experienced researchers in your field

- rapid publication on acceptance

- support for research data, including large and complex data types

- gold Open Access which fosters wider collaboration and increased citations

- maximum visibility for your research: over $100 \mathrm{M}$ website views per year

At $\mathrm{BMC}$, research is always in progress.

Learn more biomedcentral.com/submissions 